\title{
Ultramorphology of the root surface subsequent to hand-ultrasonic simultaneous instrumentation during non-surgical periodontal treatments. An in vitro study
}

\author{
Simone D. ASPRIELLO' ${ }^{1}$, Matteo PIEMONTESE², Luca LEVRINI ${ }^{3}$, Salvatore SAURO ${ }^{4,5}$ \\ 1- DDS, PhD, Institute of Dental Science, Division of Periodontology, Polytechnic University of Marche, Ancona, Italy. \\ 2- MD, DDS, Associated Professor of Periodontology, Institute of Dental Science, Division of Periodontology, Polytechnic University of Marche, Ancona, Italy. \\ 3- MD, DDS, Head of the Dental Hygiene School, Institute of Dental Science, Department of Clinical and Biology Science, University of Insubria, Varese, Italy. \\ 4- PhD, Biomaterials, Biomimetics \& Biophotonics, King's College London Dental Institute at Guy's, King's College and St. Thomas' Hospitals, Guy's Hospital, \\ London, UK. \\ 5- PhD, Department of Dental Materials, School of Dentistry, University of Granada, Spain
}

Corresponding address: Dr. Salvatore Sauro - Biomaterials, Biomimetics \& Biophotonics - King's College London Dental Institute at Guy's, King's College and St. Thomas' Hospitals - Floor 17, Guy's Hospital - London SE1 9RT, UK - Phone: +44 2071883874 - e-mail: salvatore.sauro@kcl.ac.uk

Received: October 02, 2009 - Modification: October 20, 2009 - Accepted: October 22, 2009

\section{ABSTRACT}

$\mathrm{O}$ bjective: The purpose of this study was to investigate the ultramorphology of the root surfaces induced by mechanical instrumentation performed using conventional curettes or piezoelectric scalers when used single-handedly or with a combined technique. Material and Methods: Thirty single-rooted teeth were selected and divided into 3 groups: Group A, instrumentation with curettes; Group B instrumentation with titanium nitride coated periodontal tip mounted in a piezoelectric handpiece; Group C, combined technique with curette/ultrasonic piezoelectric instrumentation. The specimens were processed and analyzed using confocal and scanning electron microscopy. Differences between the different groups of instrumentation were determined using Pearson's $\chi 2$ with significance predetermined at $\alpha=0.001$. Results: Periodontal scaling and root planing performed with curettes, ultrasonic or combined instrumentation induced several morphological changes on the root surface. The curettes produced a compact and thick multilayered smear layer, while the morphology of the root surfaces after ultrasonic scaler treatment appeared irregular with few grooves and a thin smear layer. The combination of curette/ultrasonic instrumentation showed exposed root dentin tubules with a surface morphology characterized by the presence of very few grooves and slender remnants of smear layer which only partially covered the root dentin. In some cases, it was also possible to observe areas with exposed collagen fibrils. Conclusions: The curette-ultrasonic simultaneous instrumentation may combine the beneficial effects of each instrument in a single technique creating a root surface relatively free from the physical barrier of smear layer and dentin tubules orifices partial occlusion.

Key Words: Cementum. Periodontics. Scaling. Smear layer. Microscopy electron scanning. Confocal laser scanning microscopy.

\section{INTRODUCTION}

Periodontal disease is characterized by chronic inflammatory processes caused by the presence of specific pathogen microorganisms, which trigger host response, progressive destruction of alveolar bone and apical migration of connective and epithelial attachments over time ${ }^{1,8}$.

These pathogenic microorganisms secrete endotoxins that are absorbed by the root hard tissues. Removal of the endotoxins, bacteria and calculus in affected tissues is recommended to control the inflammation and help the healing of gingival structures ${ }^{3,17}$.

The main treatment modality for periodontal health is scaling and root planing either during surgical intervention or in a non-surgical approach with the endpoint of producing a root that is 
biologically acceptable for healing processes ${ }^{6,24}$.

These mechanical procedures may be accomplished by using sonic, ultrasonic and manual instruments with the intention of removing the subgingival biofilm, calculus and endotoxins from the root surface ${ }^{9,24}$ and also to accomplish a maintainable shift in microbiota ${ }^{12}$. It is frequently necessary that even infected cementum and dentin needs to be removed when the toxic products and bacteria have penetrated into tissue , $^{4-11}$. Moreover, calcification of the bacterial biofilm left on the root surface during scaling and root-planing, which is composed primarily of calcium phosphate mineral salts deposited between and within remnants of formerly viable microorganisms, may increase the risk for plaque retention and attachment loss ${ }^{26}$.

It is well known that scaling and root planing creates a layer of organic and mineralized debris known as the smear layer that covers the surface of the instrumented roots and occludes the dentin tubules $2,14,23$.

The thickness of this smear layer usually ranges from 2-15 $\mu \mathrm{m}^{5}$ and it might be considered a contaminated physical barrier between the periodontal tissues and the root surface $13,17,20$. Ideally the procedures of scaling and root planning should leave smooth root surfaces, relatively free of smear layer and any associated calculus, bacteria or endotoxin-contaminated root cementum ${ }^{9,22}$.

The objective of this study was to investigate the ultramorphology of the root surfaces induced by mechanical instrumentation performed using conventional curettes or piezoelectric scalers when used single-handedly or with a combined technique, using scanning electron microscopy (SEM) and confocal scanning laser microscopy (CLSM). The hypothesis tested was that the periodontal instrumentation of scaling and root planing performed with a combined curette/ultrasonic technique would be able to remove the cementum and create a root surface characterized by reduced presence of smear layer when compared to singlehanded instrumentation.

\section{MATERIAL AND METHODS}

\section{Specimen Preparation}

Thirty single-rooted healthy human teeth, freshly extracted for orthodontic or surgical reasons, were used in this study. The teeth were extracted after informed consent was obtained by participants according to a treatment protocol approved by the Human Assurance Committee of the Department of Oral Surgery of the University Politecnica delle Marche, Ancona, Italy. The selection of the teeth was performed in order to have the maximum standardization of the root surface and according to the following criteria: 1 : Absence of calculus and debris; 2: Absence of dental caries; 3: Absence of any type of dental restoration; 4: No history of non-surgical periodontal treatment including scaling and root-planing prior the date of extraction. After extraction, teeth were stored in a sterile saline solution at $4^{\circ} \mathrm{C}$ for no longer than 1 month. The rationale behind the above mentioned criteria of tooth selection is based on the fact that, since the main objective of this study was focused on the morphological characteristics of the smear layer, we thought that using periodontally-affected root surfaces may present many variables that could influence the standardization of the study.

The crowns of the extracted teeth were cut approximately $1 \mathrm{~mm}$ below the cementoenamel junction (CEJ) using a high-speed diamond saw under copious water cooling. A second cut was made $3 \mathrm{~mm}$ away from the apex of the root. Subsequently, a longitudinal cut was made in order to obtain root fragments with the following dimensions of: length: $6 \mathrm{~mm}$; width: $4 \mathrm{~mm}$; depth: $2 \mathrm{~mm}$.

The specimens were washed and cleaned in an ultrasonic bath for $15 \mathrm{~min}^{3}$ and examined at $30 \times$ by stereoscopic microscopy in order to assure that no residual periodontal or gingival tissue remained on the root surface. In case of any remnant presence of periodontal tissue on the surface, it was gently removed using a Gracey-curette hand scaler (HuFriedy Mfg. Co., Inc., Chicago, IL, USA) at a very low working pressure. The specimens were then stored for no longer than 5 days in distilled water buffered to $\mathrm{pH} 7.4$ using $28 \% \mathrm{NH}_{4} \mathrm{OH}$ solution (Carlo Erba S.R.L., Milan, Italy) until further experimental procedures.

\section{Experimental Design}

The external root surface of each root fragment was left uncovered, while the remaining sides were covered by dental wax. All specimens were randomly divided into 3 groups ( $n=10 /$ group) and were instrumented by 2 operators, previously trained and calibrated during a pilot study, who performed the planing with standard angulations, the same stroking pressure during instrumentation of the specimens ${ }^{13}$ and adopting a stable lateral force using the method of Kishida, et al. ${ }^{15}$ (2004):

1. Group A (curette only). Each experimental surface was instrumented by applying 30 working strokes in vertical direction using a new and sharpened Gracey's curette 7-8 (Hu-Friedy Mfg. Co., Inc.) by 2 different operators who performed an effective planing with a $60-70^{\circ}$ working angle and applying an appropriate amount of pressure during the strokes.

2. Group B (ultrasonic scaler only). A coated titanium nitride periodontal tip mounted on a piezoelectric ultrasonic handpiece (Piezolight 5; 
Castellini Spa, Castel Maggiore, Bologna, Italy) working at $25 \mathrm{kHz}$ for $30 \mathrm{~s}$ (about 30 strokes) was used in a vertical direction under copious and constant water irrigation with a $10-15^{\circ}$ working angle and applying an appropriate amount of pressure $[\sim 5 \mathrm{~N}]$.

3. Group C (curette/ultrasonic technique). Each experimental surface was at first instrumented by applying 15 working strokes in a vertical direction using a Gracey's curette 7-8 (Hu-Friedy Mfg. Co., Inc.) performed as previously described. Subsequently, the root specimens were treated using a coated titanium nitride periodontal tip mounted on an ultrasonic handpiece (Piezolight 5, Castellini Spa) working at $25 \mathrm{kHz}$ for $15 \mathrm{~s}$ (about 15 strokes) in a vertical direction under copious water irrigation. The pressure and the angulations of working strokes used in this combined technique were the same as those used for each single handed technique.

\section{Confocal Laser Scanning Microscopy}

The specimens were imaged using a confocal laser scanning microscopy (Leica SP2 CLSM, Heidelberg, Germany) equipped with a $63 \times, 1.4$ NA oil immersion lens using $514 \mathrm{~nm}$ argon/helium ion laser illumination to evaluate the modifications induced by the experimental treatments on dentin surfaces devoid of artifacts usually induced by specimen preparation required for SEM. Reflected light from the dentin surface was detected with a photomultiplier tube using reflection filters. A z-step of $1 \mu \mathrm{m}$ was used to optically section the specimens to depths of up to $30 \mu \mathrm{m}$ below surface. The z-axis scan of the dentin surface was converted into pseudo-colour for better visualization, and compiled into both single and topographic projections using Leica SP2 CLSM image-processing software (Leica SP2 CLSM). The configuration of the system was standardized and used at the same level for the entire investigation.

\section{Scanning Electron Microscopy (SEM)}

After the CLSM investigation, all specimens from groups $A, B$ and $C$ were fixed with $4 \%$ formaldehyde in $0.2 \mathrm{M}$ phosphate buffer $(\mathrm{pH}=7.2)$ at room temperature for $24 \mathrm{~h}$. Following fixation, the specimens were dehydrated using an ascending series of graded ethyl alcohol solutions at the concentrations of $50,80,95$ and $100 \%$ for $10 \mathrm{~min}$ at each concentration. The specimens were then air-dried over-night. Prior to scanning electron microscopy examination, the specimens were mounted on SEM stubs with a silver paint, dried and then sputter coated with gold. The microscopy investigation (SEM) was performed using a scanning electron microscope (JEOL 5200, JOEL Corp. Tokyo, Japan) working at 5-10 kV. Each root specimen was considered as a sample-unit and 3 SEM micrographs were randomly obtained from each specimen, with different standardized magnifications $(\times 1,000$, $\times 2,000$ and $\times 5,000$ ) resulting in a total number of 9 images per specimen; these images were intended to be representative of the most common features observed in each sample. The micrographs were assessed by 2 examiners blinded to the experimental procedures but previously instructed during a pilot study to use the the following index of root surface and smear layer morphology characteristics, as follows: Grade 1 - thick and compact smear layer, no dentin tubules open; Grade 2 - thin smear layer, no presence of dentin tubules; Grade 3 - residues of smear debris partially occluding dentin tubules; Grade 4 - absence of smear layer on the dentin surface with exposed collagen fibrils. For each specimen, a single value was assigned after the evaluation of the 9 representative images $(\times 1,000$, $\times 2,000 \times 5,000)$, resulting in 10 values per group. The distribution of smear layer morphology grades was tested using Pearson's $\chi^{2}$ test and significance was established at $p=0.001$ and adjusted residuals were used to identify significant treatment grade interactions.

\section{RESULTS}

Periodontal treatments of scaling and root planing performed with manual, sonic or combined instrumentation induced several morphological changes on the root surface. The scanning electron micrographic appearance of the morphology of the root surface treated by hand curette (Group A) revealed a compact and multilayered smear layer (Figure $1 \mathrm{~A}$ ) characterized by the presence of superficial furrows with a distinguishing morphology similar to that of "tree-bark" (Figure 1B and C). The morphology of the surfaces of the root fragments treated with the ultrasonic scaler only (Group B) appeared irregular with few grooves on the root surfaces (Figure 2A). Higher magnification images showed that those root surfaces were covered by a porous and thin layer of debris (Figures $2 \mathrm{~B}$ and C). CLSM showed that the root surface treated by curette presented a smoother surface compare to those treated using the ultrasonic tip (Figures 3A, B). The combined manual/ultrasonic instrumentation (Group C) showed a peculiar morphology to the root surface with many differences when compared to the other treatments. The morphology of the root surfaces revealed that the cementum was completely removed with the exposure of the root dentin and dentin tubules (Figure 4A). The morphology of the root surfaces was characterized by the presence of very few grooves and a slender remnant smear layer which only partially covered the root dentin (Figure 4B). Higher magnification 

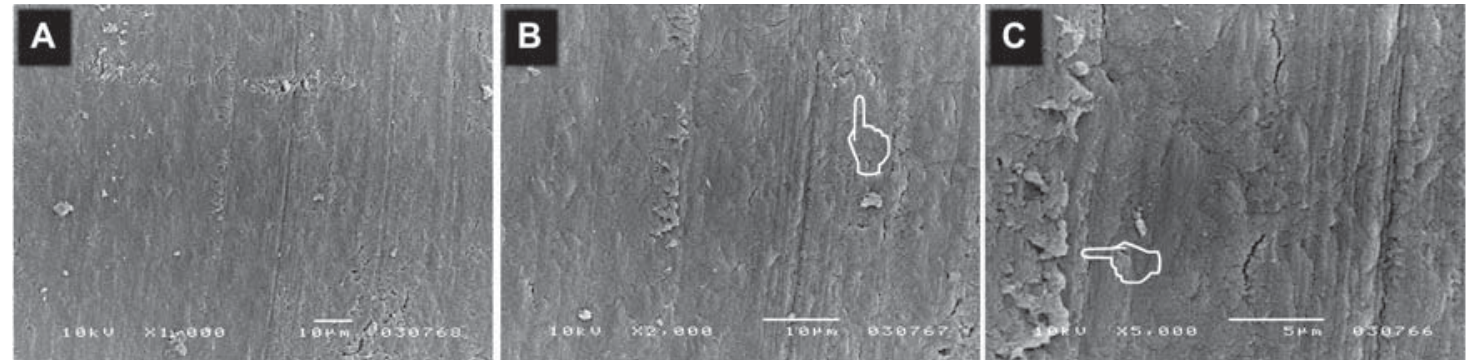

Figure 1- Scanning electron microscopy showing the morphology of the root surfaces treated with hand curettes. A: mechanical periodontal treatment with curettes creates a compact and multilayered smear layer characterized by the presence of superficial furrows; $B(\times 2,000)$ and $C(\times 5,000)$ : At higher magnification it is possible to clearly observe a distinguished morphology similar to that of "tree-bark" (pointer) induced by the working strokes of the curette. No exposed dentin tubules were observed subsequent to the mechanical periodontal treatment with curettes
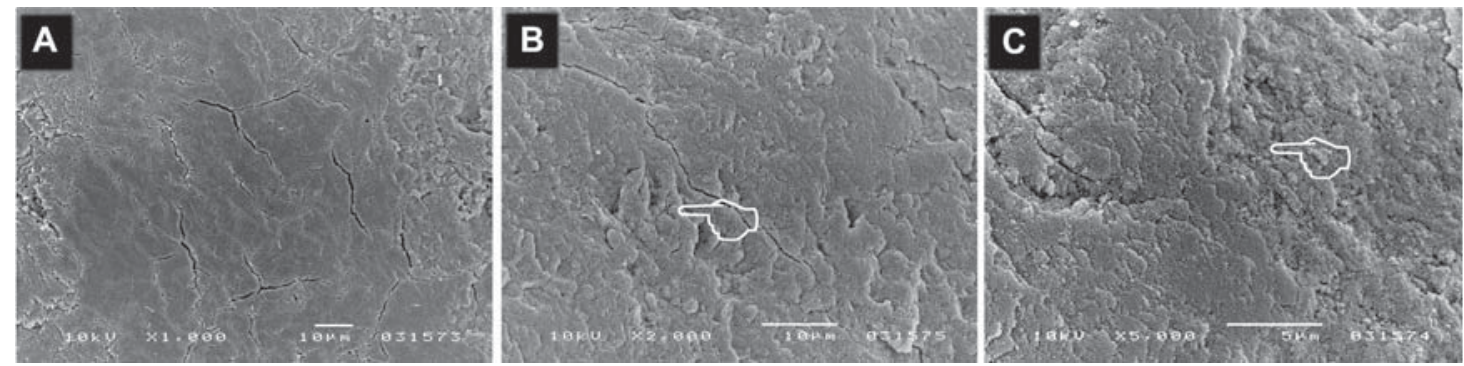

Figure 2- Scanning electron microscopy showing the morphology of the root surfaces treated with the piezoelectric scaler. A: non-surgical periodontal treatment performed with this method creates an irregular root surface with few shallow grooves; B: higher magnification $(\times 2,000)$ showing that the root cementum was not removed by the ultrasonic instrumentation but was only altered and characterized by pits and tips (pointer); C: $(\times 5,000)$ presence of a porous and thin layer of debris with no exposed dentin tubules (pointer)
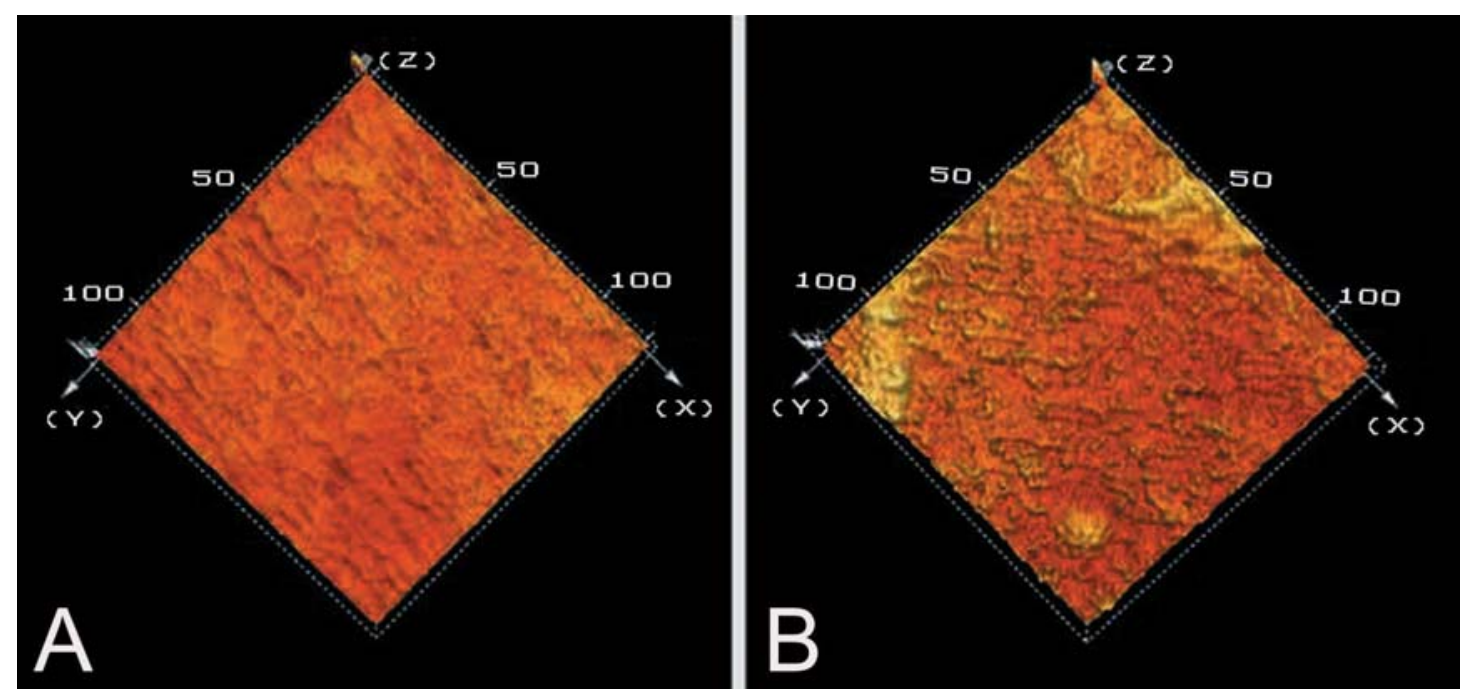

Figure 3- Confocal laser scanning microscopy topographical images. A: root surface treated with hand curettes showing a compact smear layer characterized by the presence of superficial furrows. No exposed dentin tubules were observed subsequent to the mechanical periodontal treatment with the curettes; B: root surfaces treated using the piezoelectric scaler, showing an irregular and coarse root surface with few shallow grooves pits and tips (pointer)

images showed that the remnant smear layer produced by this combined manual/ultrasonic technique partially obliterated the dentin tubules giving them a characteristic conformation similar to that of a "flute-mouthpiece" (Figure 4C). In some case, it was also possible to observe areas with exposed collagen fibrils (Figures 5A and 4B). The CLSM confirmed the results observed with SEM 

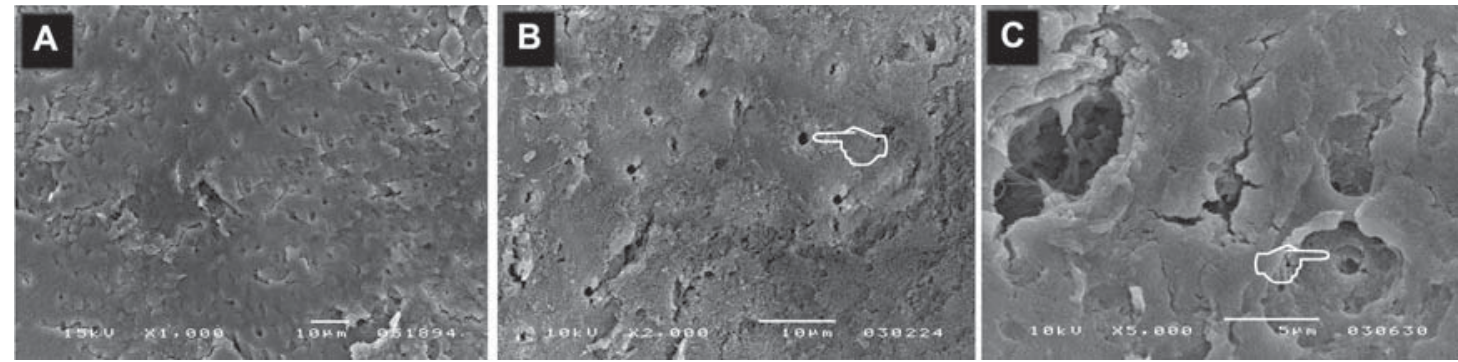

Figure 4- Scanning electron microscopy appearance of the morphology of the root surfaces treated with the simultaneous manual and ultrasonic instrumentation. Image A shows the morphology of the root surfaces characterized by very few grooves and slender remnant smear layer which only partially covered the root dentin. Image B: at higher magnification it is possible to observe that the root-cementum was completely removed with the exposure of root dentin and dentin tubules (pointer). Image $\mathrm{C}$ shows that the remnant smear layer produced by this combined manual/sonic technique obliterated the dentin tubules (pointer) and many of them had a characteristic conformation similar to the shape of a "flute-mouthpiece"
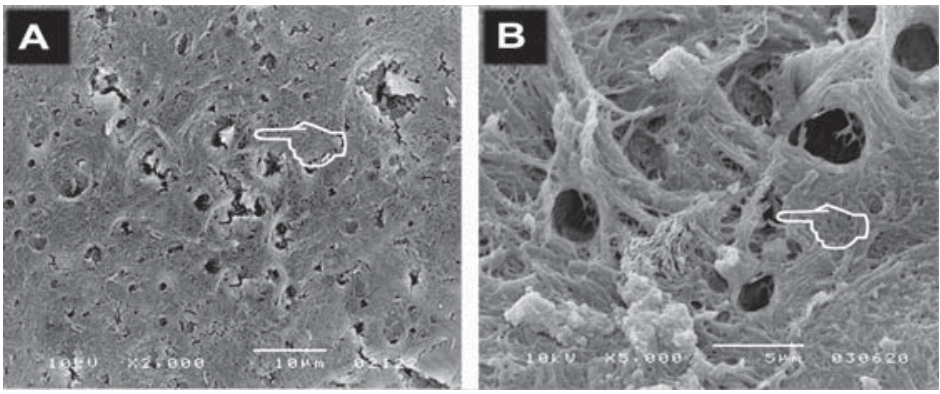

Figure 5- Scanning electron microscopy (A and B) of the morphology of root surfaces treated with simultaneous manual and ultrasonic instrumentation reveal that some areas with exposed collagen fibrils (pointer)
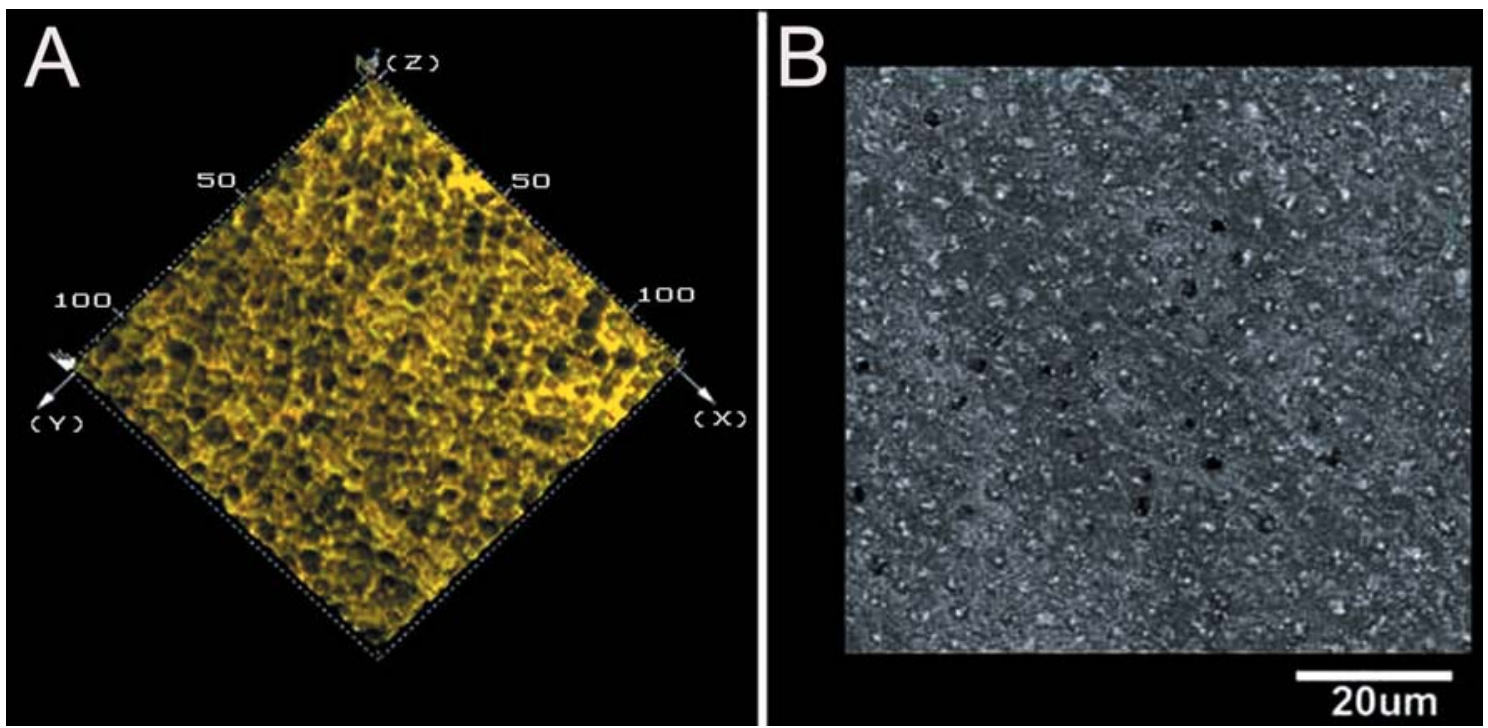

Figure 6- Confocal laser scanning microscopy topographical $(A)$ and single projection $(B)$ images of the root surfaces treated using the simultaneous curette/ultrasonic instrumentation technique showing the morphology of the root surfaces characterized by slender remnant smear layer that only partially covered the root dentin (B). It is possible to observe that the root cementum was completely removed with the exposure of root dentin and dentin tubules

showing only a slender smear layer that partially obliterated the dentin tubules (Figures 6A, B). The statistical analysis performed on the values obtained using the index of root surface and smear layer morphology characteristics showed statistical differences between the groups $(p<0.001)$ (Table $1)$. 
Table 1- Distribution of the scores for morphological characteristics of the root surface

\begin{tabular}{cccc}
\hline $\begin{array}{c}\text { Evaluation criteria } \\
\text { (scores: 1-4) }\end{array}$ & $\begin{array}{c}\text { Group A } \\
\text { (curette only) } \\
(\mathrm{n}=10)\end{array}$ & $\begin{array}{c}\text { Group B } \\
{\text { (ultrasonic scaler only) })^{\mathrm{b}}}^{(\mathrm{n}=10)}\end{array}$ & $\begin{array}{c}\text { Group C } \\
\text { (Curette/ultrasonic) }^{\mathrm{c}} \\
(\mathrm{n}=10)\end{array}$ \\
\hline Grade 1 & 10 & - & - \\
Grade 2 & - & 10 & - \\
Grade 3 & - & - & 7 \\
Grade 4 & - & - & 3 \\
\hline
\end{tabular}

*Different lower case letters indicate statistically significant differences $(P<0.001)$. The specimens were assessed using the following index of smear layer removal: (Grade 1: thick and compact smear layer, no dentinal tubules open; Grade 2: thin smear layer, no presence of dentinal tubules; Grade 3: Residues of smear debris partially occluding dentinal tubules; Grade 4: absence of smear layer on the dentine surface with exposed collagen fibrils)

\section{DISCUSSION}

Periodontally-affected root surfaces treated with conventional non-surgical periodontal treatment of scaling and root planing might be not completely free from contaminants due to the presence of a residual smear layer created during instrumentations ${ }^{11,18,27}$.

The presence of the smear layer on the instrumented root surfaces has been shown to act as a physical barrier between the periodontal tissues and the root surface ${ }^{13,17}$ unsuitable for reintegration in periodontal connective tissue ${ }^{20}$. Thus, this study investigated the ultramorphology of the smear layer created on the root surface by conventional curettes and periodontal ultrasonic scalers when used singlehandedly or with a combined instrumentation technique.

The results of this study indicated that manual and ultrasonic instrumentation induced several morphological changes on the root surface both when used single-handedly and when these instruments were used simultaneously with a combined instrumentation technique. The CLSM and SEM-ultramorphology analysis showed that manual periodontal instrumentation with a curette created a compact and multilayered smear layer on the root surface. This smear layer was characterized by the presence of superficial grooves with a "tree-bark"-like appearance, probably induced by the working strokes. Conversely, the piezoelectric instrumentation created cementum-root surfaces were rich with irregularities characterized by several pits and partially covered by a thin and porous layer of debris. No dentin tubules were exposed after this type of periodontal instrumentation indicating that the cementum was not removed from the root surface.

It has been shown that some ultrasonic scalers used on root dentin produced only some residual smear debris in relation to dentin tubules ${ }^{23}$.

Moreover, the use of ultrasonic scalers in nonsurgical periodontal treatment creates a smooth root surface with minimal damage and tight attachment of fibroblasts $26,27,33$.

Conversely, Ribeiro, et al. ${ }^{18}$ (2006) have shown that the diamond-coated tip with sonic scaler instrumentation and ultrasonic instrumentation produce similar root surface roughness, higher than curette instrumentation.

However, it is important to consider that patients who have been affected by chronic periodontal diseases for a long time and had never been treated before with any surgical or non-surgical periodontal treatments might need further and more incisive instrumentation ${ }^{7,19}$. Indeed, Rohanizadeh and Legeros $^{19}$ (2005) have demonstrated, using transmission electron microscopy (TEM), that the old calculus is in direct connection or in fusion with the tooth apatite crystals of the cement. It was shown that a very strong attachment of calculus to the tooth surface existed, more so than the cohesive strength within the calculus itself. Fractographic analysis also showed occurrence of fracture within the calculus but not at the calculus-tooth surface interface suggesting that clinical calculus removal may efficiently remove areas of the calculus prone to fracture but may still leave a part of the calculus strongly attached to the tooth surface. The remaining calculus (calcium phosphate crystals) could promote further calculus formation by attracting plaque colonization and eventual plaque calcification and/or serve as nucleating centers for calcium phosphate crystal growth. Hence, the ideal instrument should remove all the calculus from the root surfaces and leave behind a surface as smooth as possible without any iatrogenic effects ${ }^{19,25}$.

Although, Drisko ${ }^{9}$ (2001) clearly stated that ultrasonic or sonic instrumentations have similar effects to that of hand scaling and root planing when analyzing removal of biofilm, calculus and endotoxins. The choice of hand or ultrasonic instruments for root debridement is controversial. Many clinicians have advocated gentle treatment of the root surface, based on observations that 
endotoxin does not penetrate the exposed root cementum, but forms a loosely attached superficial layer on its surface ${ }^{14}$. On the other hand, under SEM observation, the curette proved to be more effective in removing the calculus-associated cementum from periodontally-affected root surfaces, when compared with the ultrasonic device, using SEM 22. Moreover, under TEM observation, curetted cementum exhibited newly synthesized fibrilar material and collagen fibrils produced by healthy, functional fibroblasts attached to the instrumented surface, and apparently oriented towards the curetted cemental surface. These results strongly suggested that improved cellular attachment can be promoted if superficial cementum is first removed by mechanical curettage ${ }^{10}$.

In this study, it was shown that when the two types of periodontal instrumentation were used simultaneously with a combined curette/ultrasonic instrumentation, the root morphology was totally different from that observed when they were used single-handedly. In the evaluation of the morphology of these root surfaces, it was revealed that the cementum was completely removed and the root dentin tubules were exposed. The root surfaces were characterized by few grooves and a very small amount of remnant smear debris, which only partially covered the dentin tubules. Moreover, at higher magnification (SEM) it was often observed that the remnant smear layer produced by this combined manual/sonic technique obliterated the dentin tubules, giving them a characteristic "flutemouthpiece" conformation.

The combined manual/ultrasonic instrumentation induced in some cases the complete removal of the smear layer and the exposure of collagen fibrils (Figure 4). It has been shown that exposure of the dentin matrix of the root surface allows formation of a proper fibrinclot, which is a determinant factor for the positive outcome of early wound healing events $^{21,27}$, thus facilitating the integration between the root surface and the healing connective tissue favoring migration and attachment of gingival fibroblasts ${ }^{2,16}$.

\section{CONCLUSION}

The combined curette/ultrasonic instrumentation, used with a shorter working time than singlehanded instrumentation, completely removed the cementum from the root surfaces and, at the same time, the use of the ultrasonic scalers allowed the decontamination of the root surfaces from the smear layer created by the curettes. Thus, as the objective of this study was the evaluation of the ultramorphology of the root surfaces and of the smear layer created after non-surgical periodontal treatments using manual and sonic instruments, it is possible to assume that the use of curettes followed by ultrasonic periodontal instruments may create root surfaces relatively free from any gross smear layer compared to the root surfaces singlehandedly instrumented by curette or ultrasonic scalers. Further studies should investigate the effects of instrumentation on the lost substance and the roughness of the root surfaces after this alternative non-surgical periodontal technique of instrumentation during scaling and root-planing. The hypothesis tested in this laboratory study that scaling and root planing performed with a combined curette/ultrasonic technique would be able to create a smooth root surface with a reduced smear layer presence when compared to singlehandedly instrumentation was accepted. Future research should be also conducted to evaluate the clinical effectiveness of this alternative technique in the healing processes and in the regeneration of connective tissues with relative reduction of pocket depth.

\section{ACKNOWLEDGEMENTS}

We are grateful to Peter Pilecki of the King's College Dental Institute for technical assistance and for editorial support.

\section{REFERENCES}

1- Armitage GC. Research, Science and Therapy Committee of the American Academy of Periodontology. Diagnosis of periodontal diseases. J Periodontol. 2003;74:1237-47.

2- Blomlöf JP, Lindskog S. Root surface texture and early cell and tissue colonization after different etching modalities. Eur J Oral Sci. 1995;103:1724.

3- Bollen CM, Quirynen M. Microbiological response to mechanical treatment in combination with adjunctive therapy. A review of the literature. J Periodontol. 1996;67:1143-58.

4- Carranza FA, Newman MG. Clinical periodontology. $9^{\text {th }}$ ed. Philadelphia: Saunders; 2002.

5- Chace R. Subgingival curettage in periodontal therapy. J Periodontol. 1974;45:107-9.

6- Cheetham WA, Wilson M, Kieser JB. Root surface debridement - an in vitro assessment. J Clin Periodontol. 1991:15:288-92.

7- Daly CG. Anti-bacterial effect of citric acid treatment of periodontally diseased root surfaces in vitro. J Clin Periodontol. 1982;9:386-92.

8- Dayan S, Stashenko P, Niederman R, Kupper TS. Oral epithelial overexpression of IL-1 alpha causes periodontal disease. J Dent Res. 2004;83:786-90.

9- Drisko CH. Nonsurgical periodontal therapy. Periodontol 2000. 2001;25:77-88.

10- Fukazawa E, Nishimura K. Superficial cemental curettage: its efficacy in promoting improved cellular attachment on human root surfaces previously damaged by periodontitis. J Periodontol. 1994;65:168-76.

11- Gamal AY, Mailhot JM. Effects of EDTA gel preconditioning of periodontally affected human root surfaces on chlorhexidine substantivity - an SEM study. J Periodontol. 2007;78:1759-66.

12- Greenstein G, Polson A. Microscopic monitoring of pathogens associated with periodontal diseases. A review. J Periodontol. 1985;56:740-7.

13- Hanes P, Polson A, Frederick T. Citric acid treatment of periodontitisaffected cementum. A scanning electron microscopic study. J Clin Periodontol. 1991;18:567-75. 
14- Kawashima H, Sato S, Kishida M, Ito K. A comparison of root surface instrumentation using two piezoelectric ultrasonic scalers and a hand scaler in vivo. J Periodontal Res. 2007;42:90-5.

15- Kishida M, Sato S, Ito K. Effects of a new ultrasonic scaler on fibroblast attachment to root surfaces: a scanning electron microscopy analysis. $J$ Periodontal Res. 2004;39:111-9.

16- Metzger Z, Weinstock B, Dotan M, Narayanan AS, Pitaru S. Differential chemotactic effect of cementum attachment protein on periodontal cells. $J$ Periodontal Res. 1998;33:126-9.

17- Polson AM, Frederick GT, Ladenheim S, Hanes PJ. The production of a root smear layer by instrumentation and its removal by citric acid. $J$ Periodontol. 1984;55:443-6.

18- Ribeiro FV, Casarin RC, Nociti FH Jr, Sallum EA, Sallum AW, Casat $M Z$. Comparative in vitro study of root roughness after instrumentation with ultrasonic and diamond tip sonic scaler. J Appl Oral Sci. 2006;14:124-9.

19- Rohanizadeh R, Legeros RZ. Ultrastructural study of calculus-enamel and calculus-root interfaces. Arch Oral Biol. 2005;50:89-96

20- Ruggeri A Jr, Prati C, Mazzoni A, Nucci C, Di Lenarda R, Mazzotti G, et al. Effects of citric acid and EDTA conditioning on exposed root dentin: an immunohistochemical analysis of collagen and proteoglycans. Arch Oral Biol. 2007;52:1-8

21- Santos FA, Pochapski MT, Leal PC, Gimenes-Sakima PP, Marcantonio E Jr. Comparative study on the effect of ultrasonic instruments on the root surface in vivo. Clin Oral Investig. 2008;12:143-50.
22- Sato K, Yoneyama T, Okamoto H, Dahlén G, Lindhe J. The effect of subgingival debridement on periodontal disease parameters and the subgingival microbiota. J Clin Periodontol. 1993;20:359-65.

23- Sauro S, Mannocci F, Watson TF, Piemontese M, Sherriff M, Mongiorgi

$R$. The influence of soft acidic drinks in exposing dentin tubules after non-surgical periodontal treatment: a SEM investigation on the protective effects of oxalate-containing phytocomplex. Med Oral Patol Oral Cir Bucal. 2007;2:E542-8.

24- Sherman PR, Hutchens LH Jr, Jewson LG. The effectiveness of subgingival scaling and root planing. II. Clinical responses related to residual calculus. J Periodontol. 1990:61:9-15.

25- White DJ. Dental calculus: recent insights into occurrence, formation, prevention, removal and oral health effect of supragingival and subgingival deposits. Eur J Oral Sci. 1997;105:508-22.

26- Wilkesjö UM, Nilvéus R, Selvig KA. Significance of early healing events on periodontal repair: a review. J Periodontol. 1992;63:158-65.

27-Zaman KU, Sugaya T, Hongo O, Kato H. A study of attached and oriented human periodontal ligament cells to periodontally diseased cementum and dentin after demineralizing with neutral and low $\mathrm{pH}$ etching solution. $J$ Periodontol. 2000;71:1094-9. 